\title{
Long-term clinical outcome and graft patency of radial artery and saphenous vein grafts in multiple arterial revascularization
}

\author{
Elfriede Ruttmann, MD, ${ }^{\mathrm{a}, \mathrm{b}}$ Marion Dietl, MD, ${ }^{\mathrm{c}}$ Gudrun M. Feuchtner, MD, ${ }^{\mathrm{d}}$ Bernhard Metzler, MD, \\ Nikolaos Bonaros, MD, ${ }^{\mathrm{b}}$ David P. Taggart, MD, ${ }^{\mathrm{f}}$ Mario Gaudino, $\mathrm{MD},{ }^{\mathrm{g}}$ and Hanno Ulmer, $\mathrm{PhD},{ }^{\mathrm{h}}$ for the \\ RADIAL Investigators
}

\section{ABSTRACT}

Objective: The long-term benefits of multiple arterial revascularization (MAR) in coronary artery bypass grafting remain uncertain. The aim of this study was to investigate the clinical outcome, graft patency, and need for subsequent target revascularization of radial artery (RA) versus saphenous vein graft in patients undergoing MAR in both patient- and graft-specific analyses.

Methods: Between 2001 and 2016, we followed 1654 patients over a median of 7.4 years in a prospective, longitudinal study. Major adverse cardiac and cerebrovascular events, graft patency, and need for revascularization were assessed through clinical manifestation, coronary angiography, or coronary computed tomography and analyzed with propensity score-adjusted Cox regression, general estimating equation, and competing risk models.

Results: Bilateral internal thoracic artery (BITA) grafting was performed in 910 patients $(55.0 \%)$, and 744 patients $(45.0 \%)$ received a left internal thoracic artery graft together with at least 1 RA graft. Patients receiving BITA, of whom 187 received an additional RA, showed improved survival (hazard ratio, $0.57 ; 95 \%$ confidence interval $[\mathrm{CI}], 0.38-0.86 ; P=.009)$, major adverse cardiac and cerebrovascular event-free survival (hazard ratio, $0.33 ; 95 \% \mathrm{CI}, 0.23-0.46 ; P<.001$ ), and lower need for repeat revascularization (subhzhard ratio, 0.59 ; 95\% CI, 0.39 $0.90 ; P=.015)$. In a subgroup of 512 patients, comparing 419 RA with 487 saphenous vein grafts, RA grafting showed a lower risk for graft occlusion (odds ratio, $0.59 ; 95 \% \mathrm{CI}, 0.47-0.73 ; P<.001$ ) and target revascularization (subhazard ratio, $0.58 ; 95 \% \mathrm{CI}, 0.43-0.78 ; P<.001)$.

Conclusions: MAR with BITA and RA grafting revealed to be the recommended strategy in coronary artery bypass grafting to achieve long-term beneficial results. The use of saphenous vein graft showed less favorable outcomes regarding patency and the need for target-vessel revascularization. (J Thorac Cardiovasc Surg 2019;158:442-50)

From the Departments of ${ }^{\mathrm{a}}$ Visceral, Transplant and Thoracic Surgery, ${ }^{\mathrm{b}}$ Cardiac Surgery (cross-appointed affiliation), ${ }^{\mathrm{d}}$ Radiology, ${ }^{\mathrm{e}}$ Cardiology, and ${ }^{\mathrm{h}}$ Medical Statistics, Informatics and Health Economics, Innsbruck Medical University, Innsbruck, Austria; ${ }^{c}$ Department of Plastic and Reconstructive Surgery, Landeskrankenhaus Feldkirch, Feldkirch, Austria; ${ }^{\mathrm{f}}$ Department of Cardiothoracic Surgery, Oxford University Hospitals NHS Trust, Oxford, United Kingdom; and ${ }^{\mathrm{g}}$ Department of Cardiothoracic Surgery, Weill Cornell Medicine, New York, NY. The RADIAL Investigators: Mario Gaudino, Weill Cornell Medicine, New York, NY; David P. Taggart, University of Oxford, Oxford, United Kingdom; Umberto Benedetto, Bristol Heart Institute, Bristol, United Kingdom; Brian Buxton, Victorian Heart Centre, Richmond, Victoria, Australia; Antonio Di Franco, Weill Cornell Medicine, New York, NY; Stephen Fremes, University of Toronto, Toronto, Canada; Leonard N. Girardi, Weill Cornell Medicine, New York, NY; Steven Goldman, University of Arizona, Tucson, Ariz; Robert Habib, The Society of Thoracic Surgeons Research Center, Chicago, Ill; William L. Holman, Alabama VA Medical Center, Birmingham, Ala; John D. Puskas, Icahn School of Medicine at Mount Sinai, New York, NY; Elfriede Ruttmann-Ulmer, University Hospital Innsbruck, Innsbruck, Austria; Thomas A. Schwann, University of Toledo, Toledo, Ohio;

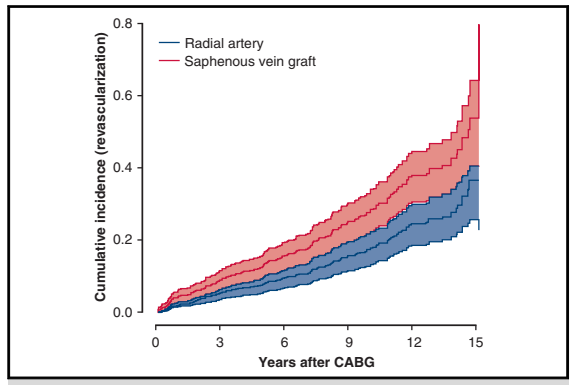

Need for subsequent target-vessel revascularization of radial artery versus saphenous vein grafts.

\section{Central Message}

The merits of radial artery over saphenous vein grafting in CABG are clearly demonstrated in this long-term follow-up study.

\section{Perspective}

MAR with BITA and RA grafting revealed to be the recommended strategy in CABG to achieve long-term beneficial results. The use of SVG showed less-favorable outcomes regarding long-term patency and the need for target-vessel revascularization.

See Commentaries on pages 451 and 453.
James Tatoulis, Royal Melbourne Hospital, Melbourne, Australia; Robert Tranbaugh, Weill Cornell Medicine, New York, NY; Giuseppe Speciale, Anthea Hospital, Bari, Italy; Giuseppe Nasso, Anthea Hospital, Bari, Italy; Neil Moat, Royal Brompton \& Harefield Trust, London, United Kingdom; Philip Hayward, Austin Hospital, Melbourne, Australia; David L. Hare, Union Road Specialist Centre, Surrey Hills, Australia; Jialin Mao, Healthcare Policy and Research, Cornell Medicine, New York, NY; Miodrag Peric, Dedinje Cardiovascular Institute and Belgrade University School of Medicine, Belgrade, Serbia; Ivana Petrovic, Dedinje Cardiovascular Institute and Belgrade University School of Medicine, Belgrade, Serbia; Kyung Jong Yoo, Yonsei University College of Medicine, Seoul, Korea. Received for publication May 7, 2018; revisions received Sept 18, 2018; accepted for publication Oct 13, 2018; available ahead of print Dec 11, 2018.

Address for reprints: Elfriede Ruttmann, MD, Department of Cardiac Surgery, Innsbruck Medical University, Anichstrasse 35, 6020 Innsbruck, Austria (E-mail: elfriede.ruttmann@i-med.ac.at). $0022-5223 / \$ 36.00$

Copyright $(2018$ by The American Association for Thoracic Surgery https://doi.org/10.1016/j.jtcvs.2018.10.135 

Abbreviations and Acronyms
AMI = acute myocardial infarction
BITA = bilateral internal thoracic artery
$\mathrm{CA}=$ coronary angiography
$\mathrm{CABG}=$ coronary artery bypass grafting
$\mathrm{CI}=$ confidence interval
CTA = computed tomography angiography
GEE = general estimating equation
HR $=$ hazard ratio
LITA $=$ left internal thoracic artery
MACCE $=$ major adverse cardiac and cerebrovascular event
MAR = multiple arterial revascularization
OMT $=$ optimal medical treatment
PCI = percutaneous coronary intervention
RA $=$ radial artery
RITA = right internal thoracic artery
SHR = subhazard ratio
SVG = saphenous vein graft

Scanning this $\mathrm{QR}$ code will take you to the article title page to access supplementary information.

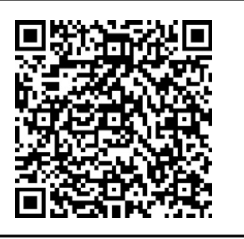

Studies of coronary artery bypass grafting (CABG) have suggested that arterial grafts are superior to saphenous vein grafts (SVG) regarding long-term patency. However, only the use of a left internal thoracic artery (LITA) to the left anterior descending artery has been reported in a large observational study and has become gold standard in coronary surgery. ${ }^{1}$ As a consequence, multiple arterial revascularization (MAR), defined as receiving 2 or more arterial grafts in CABG, has become widely accepted in younger patients with longer life expectancy. ${ }^{2}$ Currently, the 5-year interims analysis from the Arterial Revascularization trial (ART trial) has not yet shown a survival benefit among patients receiving bilateral internal thoracic arteries (BITA), possibly due to current short follow-up to adversely impact on clinical outcome. ${ }^{3}$ Moreover, a substantial proportion of patients receiving LITAs received radial arteries (RAs). ${ }^{3,4}$ The risk of sternal complications, however, has prevented a more common use of BITA, and many cardiac surgeons therefore prefer the RA to achieve MAR. ${ }^{5,6}$

The potential advantages of CABG surgery with more frequent use of arterial grafts has been reported while simultaneously dramatic improvements in percutaneous stent technologies (percutaneous coronary intervention [PCI]) have led to a substantial proportion of patients known to benefit from surgery being treated with stents. ${ }^{6,7}$ Moreover, PCI has become the mainstay for the treatment of CABG-related graft failure. ${ }^{8,9}$

In addition, computed tomography angiography (CTA) technology has evolved to be a valuable, less-invasive tool to investigate both native coronary arteries and graft patency among patients with or without previous revascularization. ${ }^{10,11}$

Most outcome studies after MAR evaluate crude survival with relatively short-term follow-up-and in the light of PCI treatment of graft failure-may only imprecisely reflect outcome and graft patency among patients undergoing MAR. ${ }^{12}$ Repeat revascularization after CABG also may occur in de novo lesions, and CABG-related graft occlusion may not necessarily mandate repeat revascularization. In contrast, a major adverse cardiac and cerebrovascular event (MACCE) may not automatically be related to graft failure. To answer these questions, this longitudinal follow-up study was implemented among patients undergoing MAR.

Therefore, the aim of this study was to investigate the clinical outcome, graft patency, and need for subsequent target revascularization of RA and SVG among patients undergoing MAR in a large prospective follow-up study. Because of its clinical importance, we also investigated BITA versus LITA grafting in this study.

\section{METHODS \\ Study Population}

In this prospective longitudinal outcome study, 1654 consecutive patients who underwent first, nonemergent MAR at the Innsbruck Medical University were followed for a median of 7.4 years between August 2001 and August 2016 (Table 1). Inclusion, exclusion criteria, and endpoint definitions for this study have been described previously. ${ }^{13}$ All patients gave informed consent, and permission for this study was obtained from the local institutional review board (approval: 21.2.2001, UN4232). In addition, we participate in the RADIAL (Radial Artery Database International ALliance) conducting research related to the RA.

\section{Diagnostic Procedures and Endpoint Definitions}

Patient data including baseline characteristics such as obesity, hypertension, diabetes, or smoking habits as well as operative data were prospectively collected in full accordance with the standards of the Quality Control Working Group of the Austrian Society of Cardiothoracic Surgery. Survival, MACCE-free survival, freedom from angina, and repeat revascularization were routinely obtained in 4- to 5-year intervals. MACCEs were defined as combined endpoints including acute myocardial infarction (AMI), stroke, cardiac-related death, and repeat revascularization. Coronary angiography $(\mathrm{CA})$ reports in patients who underwent repeated cardiac catheterization or CTA were obtained and evaluated. In case of death, the autopsy reports (if available) were obtained to discriminate cardiac from noncardiac death causes. Late death was supplemented from routine anniversary follow-up supplemented with the Social Security Death Index.

CA and CTA procedures during follow-up were reviewed and evaluated by board-certified cardiologists/radiologists (Table 2). CTA was performed using a 64-slice CT system of multiple slices according to international standardized scan parameters. An iodine contrast agent was injected intravenously and triggered into arterial phase to evaluate bypass graft patency on axial images and multiplanar reformations. In patients with repeated coronary diagnostic procedures during follow-up, only the first examination after CABG was selected 
TABLE 1. Preoperative characteristics of patients receiving first, nonemergent MAR by the use of BITA and LITA + RA from 2001 to 2016

\begin{tabular}{|c|c|c|c|}
\hline & $\begin{array}{c}\text { LITA }+ \text { RA } \pm \text { SVG } \\
(n=744 \text { patients })\end{array}$ & $\begin{array}{r}\text { BITA } \pm \text { RA } \pm \text { SVG } \\
(n=910 \text { patients })\end{array}$ & $P$ value \\
\hline Male sex & $638(85.8 \%)$ & $805(88.5 \%)$ & .1 \\
\hline Age, y & $60.2 \pm 8.1$ & $59.2 \pm 9.0$ & .019 \\
\hline Positive family history regarding premature CAD & $335(45.0 \%)$ & $549(60.3 \%)$ & $<.001$ \\
\hline BMI, $\mathrm{kg} / \mathrm{m}^{2}$ & $27.7 \pm 4.0$ & $27.3 \pm 3.9$ & .055 \\
\hline Obesity (BMI $\geq 30 \mathrm{~kg} / \mathrm{m}^{2}$ ) & $180(24.2 \%)$ & $211(23.2 \%)$ & .63 \\
\hline Previous smoking & $327(44.0 \%)$ & $447(49.1 \%)$ & .036 \\
\hline Current smoking & $143(19.2 \%)$ & $189(20.8 \%)$ & .39 \\
\hline Diabetes mellitus & $192(25.8 \%)$ & $188(20.7 \%)$ & .013 \\
\hline Insulin-dependent diabetes & $42(5.6 \%)$ & $44(4.8 \%)$ & .46 \\
\hline COPD & $160(21.5 \%)$ & $252(27.7 \%)$ & \\
\hline Mild & $120(16.1 \%)$ & $162(17.8 \%)$ & \\
\hline Moderate & $36(4.8 \%)$ & $82(9.0 \%)$ & \\
\hline Severe & $4(0.5 \%)$ & $8(0.9 \%)$ & .004 \\
\hline Preoperative creatinine, $\mathrm{mg} / \mathrm{dL}$ & $1.0 \pm 0.48$ & $0.9 \pm 0.60$ & $<.001$ \\
\hline Preoperative hemodialysis & $5(0.7 \%)$ & $14(1.5 \%)$ & .10 \\
\hline Peripheral arterial disease & $91(12.2 \%)$ & $104(11.5 \%)$ & .63 \\
\hline Cerebrovascular disease & $45(6.0 \%)$ & $58(6.4 \%)$ & .79 \\
\hline Previous cerebrovascular event & $22(3.0 \%)$ & $37(4.1 \%)$ & .23 \\
\hline Previous myocardial infarction & $135(18.1 \%)$ & $329(36.4 \%)$ & $<.001$ \\
\hline Previous PCI & $123(16.5 \%)$ & $232(25.5 \%)$ & $<.001$ \\
\hline Left main disease $(\geq 50 \%)$ & $202(27.2 \%)$ & $377(41.4 \%)$ & $<.001$ \\
\hline Isolated left main disease & $74(9.9 \%)$ & $84(9.2 \%)$ & .63 \\
\hline \multicolumn{4}{|l|}{ Severity of CAD } \\
\hline 2-vessel disease & $297(39.9 \%)$ & $170(18.4 \%)$ & \\
\hline 3-vessel disease & $447(60.1 \%)$ & $740(81.3 \%)$ & $<.001$ \\
\hline
\end{tabular}

Received procedure

$$
\begin{aligned}
& \text { LITA + RA } \\
& \text { LITA + RA } \pm \text { SVG } \\
& \text { BITA only } \\
& \text { BITA + SVG } \\
& \text { BITA + RA }
\end{aligned}
$$

$227(30.5 \%)$

$517(69.5 \%)$

$54.8 \pm 10.9$

$141(19.0 \%)$

$32(4.3 \%)$

$2.9 \pm 3.3$
$133(14.6 \%)$

$590(64.9 \%)$

$187(20.5 \%)$

$56.7 \pm 10.3$

.001

Impaired left ventricular function

Mild (35 to $<48 \%)$

Severe $(<35 \%)$

Logistic EuroSCORE
$129(14.2 \%)$

$26(2.9 \%)$

$2.4 \pm 2.7$

.006

Continuous variables are reported as mean \pm standard deviation. Dichotomous variables are reported as n (\%). LITA, Left internal thoracic artery; $R A$, radial artery; SVG, saphenous vein graft; $B I T A$, bilateral internal thoracic artery; $C A D$, coronary artery disease; $B M I$, body mass index; $C O P D$, chronic obstructive pulmonary disease; $P C I$, percutaneous coronary intervention; EuroSCORE, European System for Cardiac Operative Risk Evaluation.

for graft patency analysis. When CTA was followed by a confirming CA investigation, the result was taken from the CA examination. The CA/CTA findings were categorized according to Khot and colleagues ${ }^{14}$ as (1) occluded, (2) severely diseased ( $\geq 70 \%$ stenosis or string sign), or (3) patent.

Graft-specific information included the native target-vessel stenosis, graft type (LITA, right internal thoracic artery [RITA], RA, SVG) and information as whether the target-vessel had been subjected to previous PCI. Additional information included the proximal graft configuration-either in situ grafting or y-configurations to other arterial or venous conduits.
In patients with sequential grafting, each graft anastomosis and corresponding target-vessel was analyzed as separate graft. In addition, therapeutic interventions of each graft target-either by successful or attempted PCI or repeat $\mathrm{CABG}$-were documented to evaluate the need for target-vessel revascularization.

\section{Statistical Analysis}

Categorical variables are presented in percentages and corresponding numbers. Continuous variables are summarized with means and standard 
TABLE 2. Characteristics of 455 patients undergoing coronary diagnostic procedures (CA/CTA) after MAR

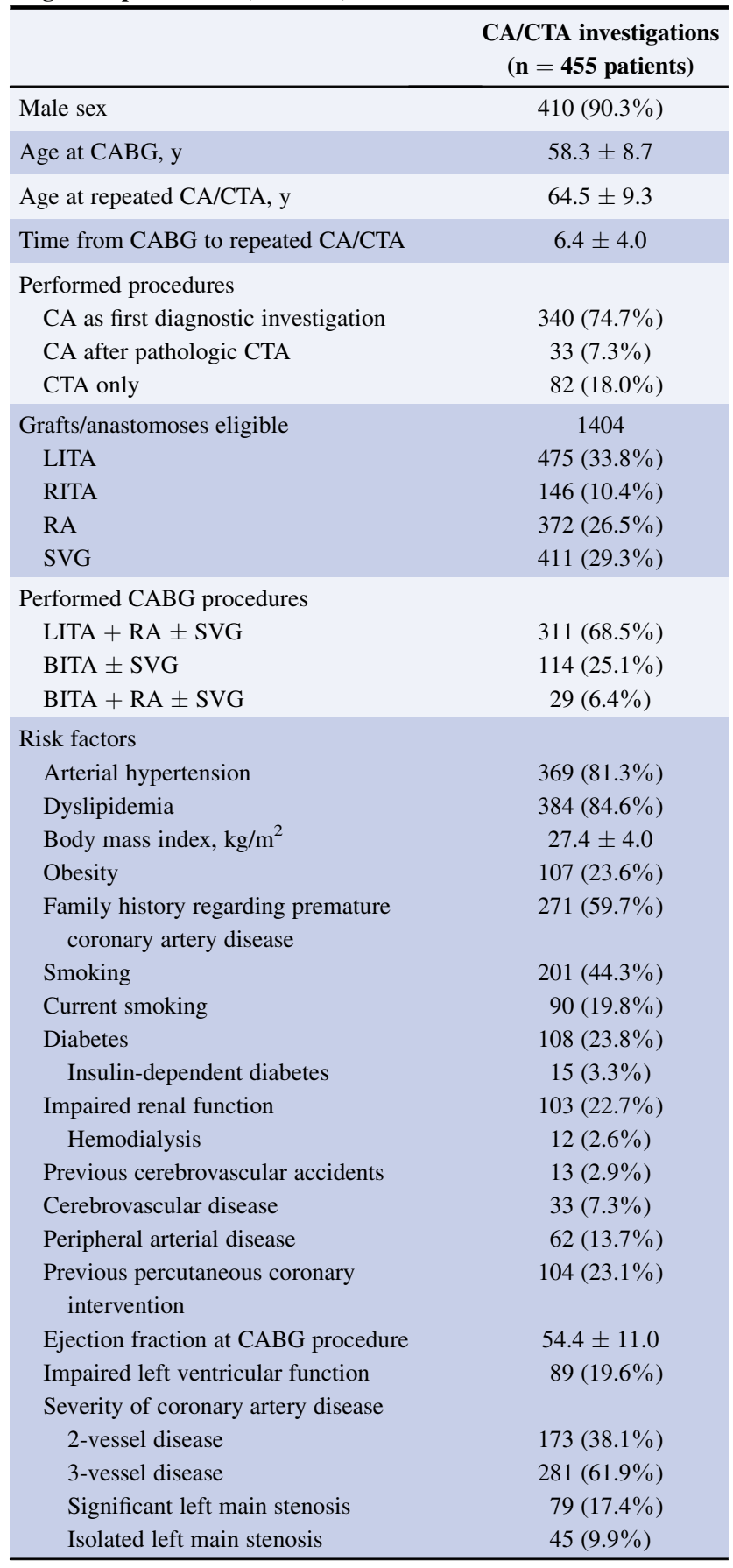

Continuous variables are reported as mean \pm standard deviation. Dichotomous variables are reported as $\mathrm{n}(\%) . C A$, Coronary angiography; $C T A$, coronary computed tomography; $C A B G$, coronary artery bypass grafting; LITA, left internal thoracic artery; $R I T A$, right internal thoracic artery; $R A$, radial artery; $S V G$, saphenous vein graft; $B I T A$, bilateral internal thoracic artery.

deviations or medians and ranges, respectively. Differences in the characteristics between the treatment groups were assessed using $\chi^{2}$ tests (categorical variables) and Mann-Whitney $U$ or $t$ test (continuous variables) as appropriate and reported using standardized differences.
The statistical analysis consisted of a patient-wise analysis (BITA vs LITA) of time-related events (overall survival, MACCE-free survival, and repeat revascularization) in the whole cohort and a graft-wise analysis (RA vs SVG) of graft patency and target revascularization in a subset of 512 patients including 57 patients with cardiac-related deaths as competing events. For both the patient-wise and graft-wise analysis, a separate propensity score was estimated with the use of logistic regression analysis. For the patient-wise analysis, a propensity score was constructed considering the following patient characteristics that potentially influence the decision to perform BITA grafting rather than LITA grafting: sex, age, diabetes, creatinine $(\mathrm{mg} / \mathrm{dL})$, hemodialysis, chronic obstructive pulmonary disease severity class, previous and current smoking, severity of coronary artery disease (either 2- or 3-vessel disease), previous cerebrovascular event, previous AMI, previous PCI, left main disease ( $>70 \%$ stenosis), ejection fraction ( $\%$ ), and a positive family history according to the definitions of the Framingham Offspring Study. ${ }^{15}$

These variables were univariably tested as already outlined, and variables showing a $P$ value less than .2 were selected to generate the propensity score. For the graft wise analysis, the same covariates $(P<.2)$ were used to generate a propensity score representing the decision for RA versus SVG grafting. Graft- and target vessel-specific variables were not included in the propensity score; the respective variables were included as covariates in the graft-wise outcome models.

In the patient-wise multivariable analyses, Cox proportional hazards regression modeling and competing risk analysis (for repeat revascularization) were used to estimate the clinical outcomes regarding cumulative survival, MACCE-free survival, and repeat revascularization comparing the use of BITA versus LITA using the propensity score as a covariate. Hazards ratios (HRs), subhazard ratios (SHRs), and their corresponding 95\% confidence intervals ( $95 \% \mathrm{CIs}$ ) were calculated and displayed. The assumption of proportional hazards was assessed graphically using log-log plots and did not contradict the application of the Cox model.

In the graft-wise multivariable analyses, a general estimating equation (GEE) model according to Zeger and Liang ${ }^{16}$ was fitted to compare RA and SVG regarding graft patency. With the GEE model, it is possible to account for multiple grafts and repeated graft patency evaluations within patients and within follow-up time. For this purpose, different correlation structures with similar results were assumed. The reported model assumes an unstructured correlation structure.

Model covariates included target vessel-specific parameters, namely graft territory (either circumflex or right coronary artery), target-vessel stenosis $(\%)$, previous PCI of the corresponding target vessel, and whether a CA or CTA investigation was performed. The GEE model was further adjusted for follow-up time and the propensity score containing clinical characteristics as outlined above and whether grafting was part of a BITA or LITA procedure. With the GEE model, odds ratios and corresponding $95 \%$ CIs were estimated.

Finally, as part of the graft-wise analyses, a competing risk model ${ }^{17}$ was applied to estimate relative risks for target-vessel revascularization comparing RA versus SV grafting. As outlined for the GEE model, covariates were the graft-specific variables with the exception of CA/CTA and a propensity score representing patient characteristics. The competing risk model was used to estimate the cumulative incidence function of RA and SVG for the need of target-vessel revascularization; SHRs and their corresponding $95 \% \mathrm{CIs}$ were calculated and displayed. Robust standard errors were used to account for the correlated (within patients) graft data.

Competing risk analysis was performed using Stata statistical software, version 14 (StataCorp College Station, Tex). Data documentation and all other statistical analyses were performed using IBM SPSS Statistics for Windows 24.0 (IBM Corp., Armonk, NY).

\section{RESULTS}

\section{Patient-Wise Comparison: BITA Versus LITA}

A total of 1654 patients undergoing first, nonemergent MAR were included; of these patients, 910 patients 


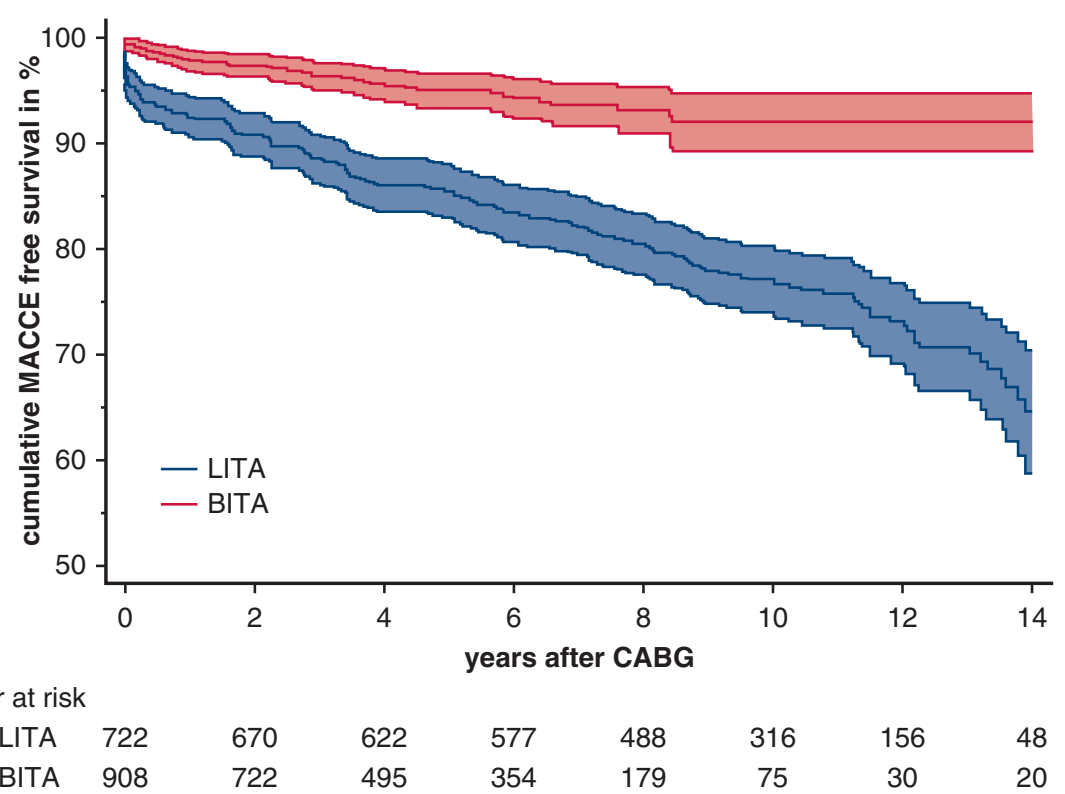

FIGURE 1. Kaplan-Meier-estimated cumulative MACCE-free survival in patients with multiple arterial revascularization, Comparison of BITA (green) versus LITA (blue); log-rank: $P<.001$. MACCE, Major adverse cardiac and cerebrovascular event; LITA, left internal thoracic artery; BITA, bilateral internal thoracic artery; $C A B G$, coronary artery bypass grafting.

$(55.0 \%)$ received $\mathrm{BITA} \pm \mathrm{RA} \pm \mathrm{SVG}$, and 744 patients $(45.0 \%)$ received LITA $+\mathrm{RA} \pm \mathrm{SVG}$. The vast majority of patients underwent on-pump CABG (1606 patients, $97.1 \%$ ), $90.9 \%$ of RITA grafts were used as in situ configurations ( 828 of 910 patients). Table 1 displays the preoperative characteristics of the study cohort. Perioperative in-hospital mortality was $1.7 \%$ (13 patients) in the LITA + RA group and $0.7 \%$ (6 patients) in the BITA group $(P=.04)$.

Propensity score-adjusted Cox regression and competing risk analysis identified BITA grafting to be associated with improved long-term survival (HR, 0.57 ; 95\% CI, 0.38-0.86, $P=.009$ ), MACCE-free survival (HR, 0.33 ; $95 \%$ CI, 0.23 $0.46, P<.001)$, and lower need for repeat revascularization (SHR, 0.59; 95\% CI, 0.39-0.90, $P=.015$ ). Overall survival at 1,5 , and 10 year(s) was $99.1 \%, 97.8 \%$, and $92.5 \%$ among patients receiving BITA and $98.3 \%, 94.8 \%$, and $87.1 \%$ in patients receiving LITA + RA, respectively. Figure 1 displays MACCE-free survival. MACCE-free survival was $98.1 \%, 95.2 \%$, and $92.2 \%$ in patients receiving BITA and $92.5 \%, 85.5 \%$, and $76.9 \%$ in patients receiving LITA. Repeat revascularization at 1, 5, and 10 year(s) after CABG was $1.0 \%, 4.3 \%$, and $8.2 \%$ in patients receiving BITA and $2.9 \%, 7.7 \%$, and $13.9 \%$ in patients receiving LITA + RA.

\section{Graft-Wise Comparison: RA Versus SVG}

A subgroup of 455 patients underwent coronary diagnostic procedures (CA/CTA) after MAR. Video 1 shows the open harvesting of a radial artery. Patient characteristics of this subgroup are shown in Table 2. Of these, 311 patients $(68.5 \%)$ received LITA + RA \pm SVG, 114 patients received BITA \pm SVG $(25.1 \%)$, and 29 patients received 3 arterial conduits $(6.4 \%)$. Regarding graft configurations, $98.9 \%$ of all investigated LITA and $78.6 \%$ of RITA grafts were in situ. Furthermore, $98.6 \%$ of all RA and $99.2 \%$ of all studied SVG grafts were used as single anastomosis conduits. Table 3 displays the indications and outcome of repeat coronary diagnostic investigations. Angina was the most

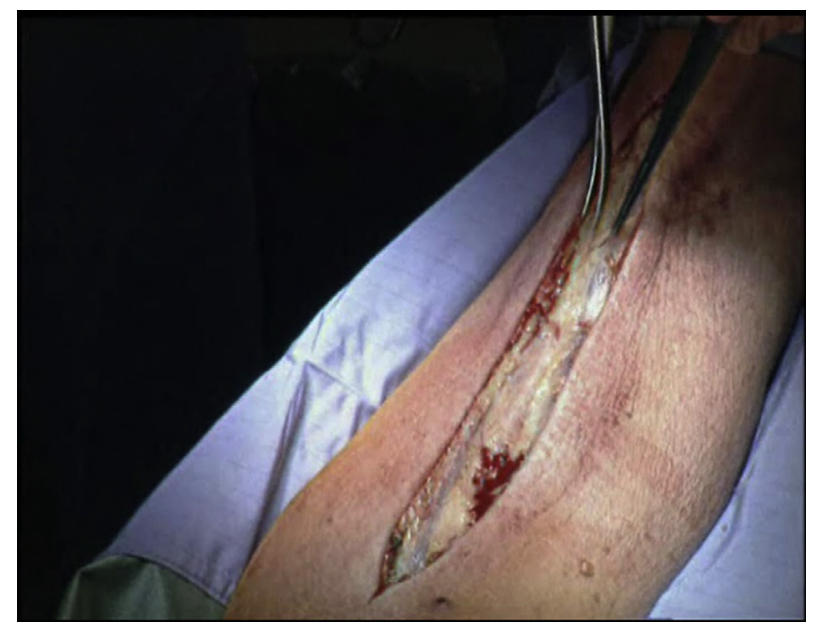

VIDEO 1. Open harvest of the radial artery. Video available at: https:// www.jtcvs.org/article/S0022-5223(18)32929-5/fulltext. 
TABLE 3. Outcome of coronary diagnostics by CA or CTA

\begin{tabular}{lc}
\hline & $\begin{array}{c}\text { CA/CTA } \\
\text { investigations } \\
(\mathbf{n}=\mathbf{4 5 5} \text { patients })\end{array}$ \\
\hline Indication for CA/CTA investigation & \\
Asymptomatic & $86(18.9 \%)$ \\
Scheduled noncoronary surgery & $24(5.3 \%)$ \\
Dyspnea/fatigue & $43(9.5 \%)$ \\
Angina/angina-like chest pain & $205(45.1 \%)$ \\
Non-ST elevation myocardial infarction & $54(11.9 \%)$ \\
ST-elevation myocardial infarction & $43(9.5 \%)$ \\
Graft configurations & \\
LITA in situ & $470(98.9 \%)$ \\
LITA free graft & $5(1.1 \%)$ \\
RITA in situ & $114(78.6 \%)$ \\
RITA free graft & $32(21.4 \%)$ \\
RA aorto-coronary single anastomosis & $366(98.6 \%)$ \\
SVG aorto-coronary single anastomosis & $407(99.2 \%)$ \\
\hline Outcome of coronary investigation & \\
Normal & $175(38.3 \%)$ \\
CABG graft disease/occlusion & $192(42.3 \%)$ \\
Progression of native CAD & $76(16.7 \%)$ \\
Complication of previous PCI & $12(2.6 \%)$ \\
Consequences resulting from coronary diagnostics & \\
None/medical & $277(60.8 \%)$ \\
Percutaneous coronary intervention & $168(37.0 \%)$ \\
Repeat CABG & $10(2.2 \%)$ \\
\hline$C A$, Coronary angiography; CTA, coronary computed tomography; $L I T A$, left internal \\
thoracic artery; $R I T A$, right internal thoracic artery; $R A$, radial artery; $S V G$, saphenous \\
vein graft; $C A B G$, coronary artery bypass grafting; $C A D$, coronary artery disease; \\
$P C I$, percutaneous coronary intervention.
\end{tabular}

frequent indication for CA/CTA among 205 patients $(45.1 \%), 86$ patients were asymptomatic $(18.9 \%)$, and 24 patients received CA/CTA before scheduled noncoronary surgery. AMI was present among 97 patients only

TABLE 4. Risk for graft occlusion in MAR patients evaluated by CA/ CTA

\begin{tabular}{lcc}
\hline & $\begin{array}{c}\text { Odds ratio } \\
(\mathbf{9 5} \% \text { confidence interval })\end{array}$ & $\boldsymbol{P}$ value \\
\hline RA vs SVG & $0.59(0.47-0.73)$ & $<.001$ \\
\hline BITA vs LITA grafting & $0.89(0.78-1.29)$ & .676 \\
\hline Graft territory RCA vs CX & $0.87(0.71-1.065)$ & .18 \\
\hline Previous target-vessel PCI & $0.92(0.68-1.24)$ & .57 \\
\hline $\begin{array}{l}\text { Target-vessel stenosis (\%) } \\
\text { CTA vs CA performed }\end{array}$ & $0.99(0.99-1.01)$ & .82 \\
\hline $\begin{array}{l}\text { Propensity score (clinical } \\
\text { characteristics) }\end{array}$ & $2.0(1.37-2.84)$ & $<.001$ \\
\hline $\begin{array}{l}\text { Odds ratios were estimated with a general estimating equation model accounting for } \\
\text { multiple grafts and repeated graft evaluations within patients and within follow-up } \\
\text { time. } R A, \text { Radial artery; } S V G \text {, saphenous vein graft; } B I T A, \text { bilateral internal thoracic } \\
\text { artery; } L I T A, \text { left internal thoracic artery; } R C A, \text { right coronary artery; } C X, \text { circumflex } \\
\text { artery; } P C I \text {, percutaneous coronary intervention; } C T A, \text { coronary computed tomogra- } \\
\text { phy; } C A, \text { coronary angiography. }\end{array}$ &
\end{tabular}

TABLE 5. Risk for repeat target-vessel revascularization in MAR patients evaluated by $\mathrm{CA}$

\begin{tabular}{lcc}
\hline & $\begin{array}{c}\text { SHR }(\mathbf{9 5} \% \text { confidence } \\
\text { interval) }\end{array}$ & $\boldsymbol{P}$ value \\
\hline RA vs SVG & $0.58(0.43-0.78)$ & $<.001$ \\
BITA vs LITA grafting & $0.54(0.36-0.81)$ & .003 \\
Graft territory RCA vs CX & $0.85(0.79-1.43)$ & .54 \\
Previous target-vessel PCI & $0.83(0.51-1.36)$ & .46 \\
Target-vessel stenosis (\%) & $0.99(0.98-1.01)$ & .53 \\
$\begin{array}{l}\text { Propensity score (clinical } \\
\text { characteristics) }\end{array}$ & $0.14(0.001-3.02)$ & .21 \\
\hline
\end{tabular}

SHRs were estimated with competing risk analysis accounting for patients with premature cardiovascular death. $S H R$, Subhazard ratio; $R A$, radial artery; $S V G$, saphenous vein graft; BITA, bilateral internal thoracic artery; LITA, left internal thoracic artery; $R C A$, right coronary artery; $C X$, circumflex artery; $P C I$, percutaneous coronary intervention.

(21.4\%). Among 174 investigations (38.3\%), CA/CTA revealed normal findings, in 42.3\% (192 patients) disease or occlusion of at least 1 conduit was diagnosed. Progression of native coronary artery disease independent from CABG graft supply was present among 76 patients $(16.7 \%)$, and complications resulting from previous PCI were found among 12 patients $(2.6 \%)$. In $60.8 \%$ of all diagnostic procedures, findings resulted in conservative or optimal medical treatment (OMT), 37.0\% received repeat revascularization by PCI and 10 patients underwent repeat CABG.

GEE modeling based on 419 RA grafts and 487 SVGs revealed RA grafting to be associated with significantly lower risk for graft disease/occlusion (odds ratio, 0.59; 95\% CI, $0.47-0.73, P<.001$; see Table 4 ). At a mean of follow-up of 6.5 years, graft occlusion was estimated $26 \%$ for RA and $43 \%$ of SVG.

Competing risk analysis identified RA grafting associated with lower need for subsequent target-vessel revascularization (SHR, 0.58; 95\% CI, 0.43-0.78, $P<.001$; see Table 5). Figure 2 displays the cumulative incidence function of RA versus SVG regarding repeat target-vessel revascularization.

\section{DISCUSSION}

Our study analyzed graft patency among 1654 patients at risk with a median follow-up of 7.4 years undergoing first, nonemergent MAR. We were not only able to analyze crude endpoints but also investigated graft patency among patients undergoing CA/CTA during frequent follow-up. Both the individual and the graft-specific analysis showed conclusive and reproducible results. The use of RITA as second conduit was associated with improved survival and lower rate for future cardiovascular events compared with LITA + RA. However, a long-term benefit of the RA over SVG has been a matter of debate due to the lack of 


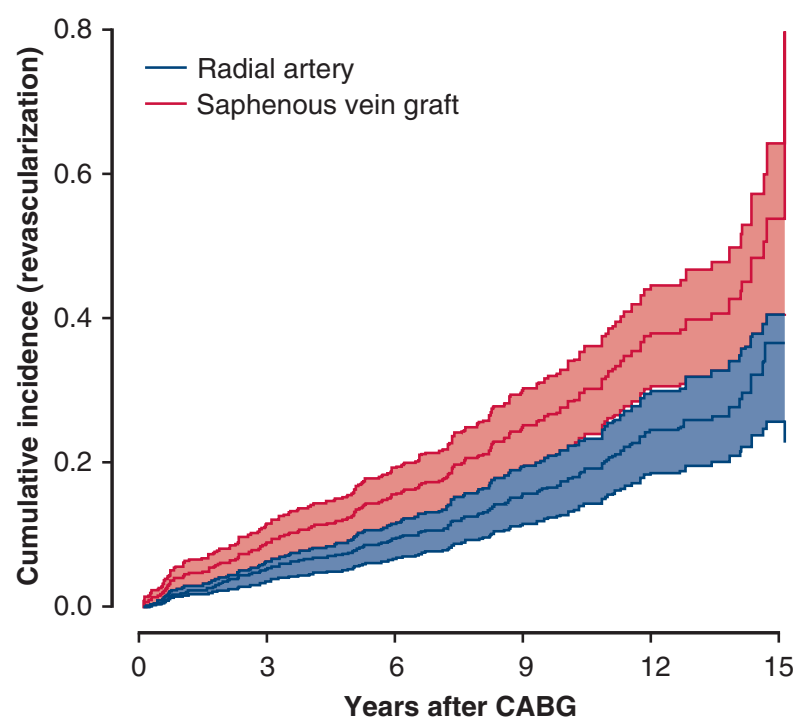

FIGURE 2. Cumulative incidence of repeat target-vessel revascularization of RA (subhazard ratio, $0.58 ; 95 \%$ confidence interval, 0.43-0.78; $P<.001)$ versus $\mathrm{SVG}$ in propensity score-adjusted competing risk analysis. $C A B G$, Coronary artery bypass grafting.

sufficient in-depth studies with follow-up periods beyond 5 years, not considering that repeat revascularization might not always be related to CABG-related graft failure. ${ }^{13,18-21}$

In our study, RA grafting was associated with significantly greater graft patency and lower need for targetvessel revascularization even after adjustment for relevant clinical conditions and target vessel-specific parameters such as target-vessel stenosis, graft territory, or previous target-vessel PCI. Furthermore, stratified for the indication for repeated CA/CTA, the divergence between RA and SVG patency was even greatest in patients with AMI. Therefore, these results implicate a strong need for the use of more arterial grafts especially of RITA and additional RA as a third graft of choice. ${ }^{12}$

The results of our study are almost identical to our very recently published meta-analysis of randomized controlled trials comparing RA versus SVG performance for $\mathrm{CABG}{ }^{22}$ In this study with comparable numbers of conduits, the incidence of adverse cardiac events was significantly lower in association with RA grafts. Moreover again, the use of RA was associated with lower risk for repeat revascularization at 5 years' follow-up. Both studies-from patients recruited in randomized clinical trials and from the actual all-comer patients-showed reproducible treatment effect using the RA rather than SVG, indicating clinical translation from randomized trials to daily, real-world settings. However, after 5-year follow-up, the working group metaanalysis has not yet shown a survival benefit of RA grafting. Tranbaugh and colleagues ${ }^{23}$ compared the outcome of 1560 propensity-score matched LITA $+\mathrm{RA} \pm \mathrm{SVG}$ patients with conventional $\mathrm{CABG}$ and found significantly lower mortality in the RA group. Their 10-year survival in the LITA $+\mathrm{RA} \pm \mathrm{SVG}$ group was identical to the overall survival of our LITA + RA \pm SVG patients. In symptomdriven CA after a mean follow-up of 4.3 years, unadjusted RA graft patency was significantly greater compared with SVG.

Locker and colleagues ${ }^{20}$ investigated the very long-term survival among patients receiving either conventional CABG or MAR in a large population of 8622 patients. They observed a significant survival benefit of MAR at 10 and 15 years compared with a matched population receiving conventional CABG. Furthermore, the results were reproducible for both sexes and older patients, concluding that MAR should be proven among greater-risk subgroups. Another multicenter study has investigated the merit of MAR with crude survival ascertained by the Social Security Death Index only and have found a significant greater survival among patients undergoing MAR. ${ }^{24}$

Current randomized trials have shown intermediate RA results only and our long-term investigation demonstrates significant advantage of the RA over SVG especially beyond 5 years after CABG among a population receiving MAR only. SVG patency exponentially declined after 6 to 7 years of follow-up, and therefore most current outcome studies may be more likely to display technical errors rather than any long-term graft degeneration.

Another study conducted by the Cleveland Clinic investigated all $\mathrm{CA}$ procedures after $\mathrm{CABG}$ involving at least 1 RA but could not relate this to any clinical outcome regarding the whole patient population at risk. ${ }^{14}$ Although they found an increased failure rate among RA grafts compared with SVG, a number of potential facts need to be acknowledged. (1) The mean follow-up time from CABG to CA was only 1.6 years; therefore, corresponding graft patency in this study may almost exclusively display early technical graft failure rather than any long-term merit of RA and SVG. (2) Sequential grafting was extensively performed among $42 \%$ of all RA grafts but only in $18 \%$ of SVG adding competitive flow, especially for the RA. (3) Only $11.7 \%$ of investigated RITA grafts remained in situ, in contrast to $78.6 \%$ of our studied RITA grafts, where our results showed significantly greater patency for in situgrafted RITA. (4) As this study was a graft/anastomosesspecific analysis, adjustment for vessel-specific parameters was not performed.

In our study, a very homogenous surgical technique was applied, namely the vast majority of patients were operated on-pump with predominantly in situ RITA configurations and single anastomoses of non-ITA conduits. Moreover, the recently published 5-year results from the ROOBY-FS (The Department of Veterans Affairs "Randomized On/ Off Bypass") trial demonstrated greater rates of death and MACCE events in patients undergoing off-pump coronary revascularization; therefore, based on the low frequency 
of off-pump surgery among patients undergoing MAR, this parameter may be ignorable as a possible confounder. ${ }^{25}$

CTA has become a reasonable tool for coronary diagnostics within the past decade and is gaining increasing importance in the long-term surveillance after CABG. The high accuracy of CTA allied to the greater vascular complication rate during $\mathrm{CA}$ in $\mathrm{CABG}$ patients in contrast with the low need for repeat revascularization among nonischemic patients suggests that CTA investigations should be used more frequently. ${ }^{10,11,26,27}$

In our analysis, RA patency was superior to SVGs, and this effect was independent of age, indicating that even older patients may profit from additional arterial grafts. These findings are supported by Benedetto and Codispoti, ${ }^{28}$ who reported that additional RA grafting improved allcause mortality in patients undergoing $\mathrm{CABG}$ up to the age of 70 years.

Furthermore, as women demonstrated lower graft patency among non-ITA grafts, it could be argued that women may be more likely to benefit from both ITAS and RA. Dimitrova and colleagues ${ }^{29}$ found a significant survival benefit at 15 years among women receiving RA instead of SVG. Moreover, MAR is less likely performed among women and patency rates of arterial grafts were not significantly different between sexes but SVG patency was lower in women. ${ }^{30}$

The greater risk of sternal wound complications has prevented a more common use of BITA. However, the sternal wound complication rate was even lower among patients undergoing BITA compared with LITA + RA \pm SVG in our series $(2.1 \%$ vs $4.0 \%$, $P=.02$ ). This ongoing step-wise decline of sternal complications is explainable as follows: first, the use of skeletonized grafts in BITA; second, the use of augmented and parasternal wires providing greater stability; and third, the administration of teicoplanine, which has significantly reduced the incidence of sternal complications. ${ }^{31}$ Moreover, recently we have introduced prophylactic negative pressure wound therapy (Kerlix; Acelity, San Antonio, Tex) among patients undergoing BITA. As we have seen improved results with the use of RITA and RA together with a declining sternal complication rate, we have switched to an almostobligatory use of BITA grafting at our center. ${ }^{13,31}$

There are several limitations-one might argue that SVGs have solely been grafted to tertiary important vessels and this may be responsible for the lower patency rates of SVG. However, we have clearly shown in a second analysis using target-vessel revascularization as primary endpoint that SVG-grafted targets were more likely to undergo repeat target revascularization compared with RA, underlining at least comparable importance of the SVGgrafted targets. The longer follow-up of patients in the LITA + RA \pm SVG group compared with BITA group is a further limitation for the interpretation of the findings. However, even despite shorter follow-up in the BITA group, there is a clear difference between early- and long-term outcome, supporting the benefit of BITA. Moreover, we cannot account for missing covariates.

Another annotation has to be mentioned-namely that during this very long period-we have gained increasing confidence to provide patients more likely with BITA. According to a stepwise modification of our surgical technique, we were able to lower sternal complications to a nearly never-happens event.

The additional use of RITA and RA is associated with a lower need for future revascularization procedures in the long-term follow-up after CABG. In the SYNTAX (Synergy between Percutaneous Coronary Intervention with Taxus and Cardiac Surgery) trial at 5 years, it has been clearly shown that early repeat revascularization was an independent predictor of future death and MACCE events. ${ }^{32}$ There has been a shift in CABG surgery toward patients in their 50s and 60s-as older patients will be more likely to be treated by culprit lesion or multiple-vessel PCIand these patients require an "insurance for life." If CABG surgery wants to survive in an era of multivessel PCI with lacking realistic long-term studies-we have to implement MAR as treatment of choice.

Graft occlusion, however, is a multifactorial phenomenon based on intrinsic factors such a competitive flow, thrombosis, oxidative stress, and endothelial dysfunction. $^{33,34}$ Extrinsic OMT is the second mainstay after CABG. As $92 \%$ of our presented MAR patients received frequent controls by a cardiologist, we are confident that the vast majority of our patients received OMT.

In conclusion, both the clinical and conduit-related outcomes of this large long-term investigation provide clear answers to 2 important issues in CABG. The results clearly indicate that the use of both in situ ITAs is advantageous and that the use of RA grafting demonstrates superior graft patency with lower need for target revascularization compared with SVG.

\section{Conflict of Interest Statement}

Authors have nothing to disclose with regard to commercial support.

\section{References}

1. Lytle BW, Blackstone EH, Loop FD, Houghtaling PL, Arnold JH, Akhrass R, et al. Two internal thoracic artery grafts are better than one. J Thorac Cardiovasc Surg. 1999;117:855-72.

2. Habib RH, Dimitrova KR, Badour SA, Yammine MB, El-Hage-Sleiman AKM, Hoffman DM, et al. CABG versus PCI. Greater benefit in long-term outcomes with multiple arterial bypass grafting. J Am Coll Cardiol. 2015;66:1417-27.

3. Taggart DP, Altman DG, Gray AM, Lees B, Gerry S, Benedetto U, et al; for the ART Investigators. Randomized trial of bilateral versus single internal thoracicartery grafts. N Engl J Med. 2016;375:2540-9.

4. Gaudino M, Ruel M, Taggart DP, the ATLANTIC Alliance. Blaise Pascal and the evidence on the use of multiple arterial grafts for coronary artery bypass surgery 
after the interim analysis of the arterial revascularization trial. Curr Opin Cardiol. 2017;32:590-3.

5. Collins P, Webb CM, Chong CF, Moat NE, for the radial Artery Versus Saphenous Vein Patency (RSVP) Trial Investigators. Radial artery versus saphenous vein patency randomized trial. Five-year angiographic follow-up. Circulation. 2008:117:2859-64.

6. Benedetto U, Angeloni E, Refice S, Sinatra R. Radial artery versus saphenous vein graft patency: meta-analysis of randomized controlled trials. J Thorac Cardiovasc Surg. 2010;139:229-31.

7. Morice MC, Serruys PW, Kappetein AP, Feldman TE, Stahle E, Colombo A, et al. Five-year outcomes in patients with left main disease treated with either percutaneous coronary intervention or coronary artery bypass grafting in the synergy between percutaneous coronary intervention with taxus and cardiac surgery trial. Circulation. 2014;129:2388-94.

8. Leitner J, Vlachos HA, Selzer F, Jamal SM, Kip KE, Williams DO, et al. Outcomes of drug-eluting stents for protected left main coronary artery disease (from the Multicenter, United States DEScover registry). Am J Cardiol. 2012; 109:466-70

9. Bangalore S, Guo Y, Samadashvili Z, Blecker S, Hannan EL. Revascularization in patients with multivessel coronary artery disease and severe left ventricular dysfunction. Everolimus-eluting stents versus coronary artery bypass graft surgery. Circulation. 2016;133:2132-40.

10. Naoum C, Berman DS, Ahmadi A, Blanke P, Gransar H, Shaw LJ, et al. Predictive value of age- and sex-specific nomograms of global plaque burden on coronary computed tomography angiography for major cardiac events. Circ Cardiovasc Imaging. 2017;10:e004896.

11. Feuchtner G, Kerber J, Burghard P, Dichtl W, Friedrich G, Bonaros N, et al. The high-risk criteria low-attenuation plaque $<60 \mathrm{HU}$ and the napkin-ring sign are the most powerful predictors of MACE: a long-term follow-up study. Eur Heart J Cardiovasc Imaging. 2016;18:772-9.

12. Gaudino M, Puskas JD, Di Franco A, Ohmes LB, Iannaccone M, Barbero U, et al Three arterial grafts improve late survival. A meta-analysis of propensitymatched studies. Circulation. 2017;135:1036-44

13. Ruttmann E, Fischler N, Sakic A, Chevtchik O, Alber H, Schistek R, et al. Second internal thoracic artery versus radial artery in coronary artery bypass grafting: a long-term, propensity score-matched follow-up study. Circulation. 2011;124: 1321-9.

14. Khot UN, Friedman DT, Petterson G, Smedira NG, Li J, Ellis SG. Radial artery bypass grafts have an increased occurrence of angiographically severe stenosis and occlusion compared with left internal mammary arteries and saphenous vein grafts. Circulation. 2004;109:2086-91.

15. Lloyd-Jones DM, Nam BO, D’Agostino RB, Levy D, Murabito JM, Wang TJ, et al. Parental cardiovascular disease as a risk factor for cardiovascular disease in middle-aged adults. JAMA. 2004;291:2204-11.

16. Zeger SL, Liang KY. Longitudinal data analysis for discrete and continuous outcomes. Biometrics. 1986;42:121-30.

17. Fine JP, Gray RJ. A proportional hazards model for the subdistribution of a competing risk. J Am Stat Assoc. 1999;94:496-509.

18. Navia D, Vrancic M, Piccinini F, Camporrotondo M, Thierer J, Gil C, et al. Is the second internal thoracic artery better than the radial artery in total arterial offpump coronary artery bypass grafting? A propensity score-matched follow-up study. J Thorac Cardiovasc Surg. 2014;147:632-8.

19. Tatoulis J, Buxton BF, Fuller JA. The right internal thoracic artery: the forgotten conduit - 5,766 patients and 991 angiograms. Ann Thorac Surg. 2011;92:9-15.
20. Locker C, Schaff HV, Dearani JA, Joyce LD, Park SJ, Burkhardt HM, et al. Mul tiple arterial grafts improve late survival of patients undergoing coronary artery bypass graft surgery: analysis of 8622 patients with multivessel disease. Circula tion. 2012;28:1023-30.

21. Tranbaugh RF, Dimitrova KR, Friedmann P, Geller CM, Harris LJ, Stelzer P, et al. Coronary artery bypass grafting using the radial artery: clinical outcomes, patency, and need for re-intervention. Circulation. 2012;126:S170-5.

22. Gaudino M, Benedetto U, Fremes S, Biondi-Zoccai G, Sedrakyan A, Puskas JD, et al; for the RADIAL Investigators. Radial-artery or saphenous-vein grafts in coronary-artery bypass surgery. $N$ Engl J Med. 2018;378:2069-77.

23. Tranbaugh RF, Dimitrova KR, Friedmann P, Geller CM, Harris LJ, Stelzer P, et al. Radial artery conduits improve long-term survival after coronary artery bypass grafting. Ann Thorac Surg. 2010;90:1165-72.

24. Schwann TA, Hashim SW, Badour S, Obeid M, Engoren M, Tranbaugh RF, et al Equipoise between radial artery and right internal thoracic artery as the second arterial conduit in left internal thoracic artery-based coronary artery bypass graft surgery: a multi-institutional study. Eur J Cardiothorac Surg. 2016;49:188-95.

25. Shroyer AL, Hattler B, Wagner TH, Collins JF, Baltz JH, Quin JA, et al; for the Veterans Affairs ROOBY-FS Group. Five-year outcomes after on-pump and offpump coronary artery bypass. N Engl J Med. 2017;377:623-32.

26. Fuchs S, Stabile E, Kinnaird TD, Mintz GS, Gruberg L, Canos DA, et al. Stroke complicating percutaneous coronary interventions: incidence, predictors, and prognostic implications. Circulation. 2002;106:86-91.

27. Ritsinger V, Saleh N, Lagerqvist B, Norhammar A. High intervention rate after a first percutaneous coronary intervention in patients with diabetes mellitus: results from the Swedish coronary angiography and angioplasty registry. Circ Cardiovasc Interv. 2015;8:e002328.

28. Benedetto U, Codispoti M. Age cutoff for the loss of survival benefit from use of radial artery in coronary artery bypass grafting. J Thorac Cardiovasc Surg. 2013; 146:1078-85.

29. Dimitrova KR, Hoffman DM, Geller CM, Ko W, Lucido DJ, Dincheva GR, et al Radial artery grafting in women improves 15 -year survival. J Thorac Cardiovasc Surg. 2013;146:1467-73

30. Fukui T, Takanashi S. Gender differences in clinical and angiographic outcomes after coronary artery bypass grafting. Circ J. 2010;74:2103-8.

31. Sakic A, Chevtchik O, Kilo J, Schistek R, Mueller LC, Ulmer H, et al. Simple adaptions of surgical technique to critically reduce the risk of postoperative sternal complications in patients receiving bilateral internal thoracic arteries. Interact Cardiovasc Thorac Surg. 2013;17:378-82.

32. Parasca CA, Head SJ, Milojevic M, Mack MJ, Serruys PW, Morice MC, et al; for the SYNTAX Investigators. Incidence, characteristics, predictors, and outcomes of repeat revascularization after percutaneous coronary intervention and coronary artery bypass grafting. J Am Coll Cardiol. 2016:9:2493-507.

33. Gaudino M, Antoniades C, Benedetto U, Deb S, Di Franco A, Di Giammarco G, et al; the ATLANTIC (Arterial Grafting International Consortium) Alliance. Mechanisms, consequences, and prevention of coronary graft failure. Circula tion. 2017:136:1749-64.

34. Ruel M, Kulik A. Suboptimal medical therapy after coronary revascularization. A missed opportunity. J Am Coll Cardiol. 2018;71:603-5.

Key Words: coronary artery bypass grafting (CABG), multiple arterial revascularization (MAR), graft failure, radial artery (RA), saphenous vein graft (SVG) 